\title{
Care, disability and HIV in East Africa: diverging or interconnected concepts and practices?
}

Article

Accepted Version

Evans, R. and Atim, A. (2011) Care, disability and HIV in East Africa: diverging or interconnected concepts and practices? Third World Quarterly, 32 (8). pp. 1437-1454. ISSN 1360-2241 doi: https://doi.org/10.1080/01436597.2011.604517 Available at https://centaur.reading.ac.uk/22701/

It is advisable to refer to the publisher's version if you intend to cite from the work. See Guidance on citing.

Published version at: http://dx.doi.org/10.1080/01436597.2011.604517

To link to this article DOI: http://dx.doi.org/10.1080/01436597.2011.604517

Publisher: Routledge

All outputs in CentAUR are protected by Intellectual Property Rights law, including copyright law. Copyright and IPR is retained by the creators or other copyright holders. Terms and conditions for use of this material are defined in the End User Agreement.

www.reading.ac.uk/centaur

\section{CentAUR}


Central Archive at the University of Reading

Reading's research outputs online 


\title{
Special issue 'Disability in the Global South', Third World Quarterly journal
}

Authors: Ruth Evans and Agnes Atim

Dr. Ruth Evans

Lecturer in Human Geography

Department of Geography and Environmental Science

University of Reading

Whiteknights PO Box 227

Reading RG6 6AB

UK.

Email: R.Evans@ reading.ac.uk.

Ms. Agnes Atim

Executive Director

National Community of Women Living with HIV and AIDS in Uganda (NACWOLA),

Kampala

Uganda

Email: agnesapea@gmail.com

Title of research paper: Care, disability and HIV in East Africa: diverging or interconnected concepts and practices?

\begin{abstract}
Recent research and policy has recognised the central role of unpaid care-givers (often women and girls) in providing care for people living with HIV in the global South. Disability rights perspectives, however, challenge the language of 'care' and 'dependence'. Disabled people's views have often been overlooked in global policy debates about care, while organisations of people living with HIV have tended to advocate for their rights in isolation from disabled people's organisations. Drawing on qualitative research with women living with HIV and children caring for them in Tanzania and on learning from the National Community of Women Living with HIV and AIDS in Uganda (NACWOLA), this paper explores the divergences and interconnections between the concepts and practices of care, disability and HIV in the context of East Africa. The research reveals commonalities between women with HIV's embodied experiences of a fluctuating life-limiting illness and disabled people's experiences of hidden impairments and chronic illnesses. Emotional interactions between children and parents/relatives living with HIV challenge assumptions about the 'dependence' and 'autonomy' of care-givers and care-recipients. Despite the development of interdependent caring relations, mutual trust and responsibility, both caregivers and people living with HIV in Tanzania experience 'diminished autonomy' and relative powerlessness in relation to the limited material, healthcare and social supports available in much of the global South. Learning from NACWOLA in Uganda, however, suggests that the participation of people living with HIV, including disabled people, in homebased care and in peer support groups can enhance 'relational autonomy' for both care-givers and care-recipients. We reflect on opportunities and challenges for mutual learning and transnational cross-movement advocacy by disabled people, people living with HIV and care-

(C) Ruth Evans and Agnes Atim, 2011. Please cite as: Evans, R. and Atim, A. (2011) 'Care, Disability and HIV in Africa: diverging or interconnected concepts and practices?', Third World Quarterly, 32(8): 1437-1454.
\end{abstract}


givers, in recognition of the common vulnerabilities, power inequalities and dependencies that these groups experience.

\section{Introduction}

The HIV and AIDS epidemic in Eastern and Southern Africa has had major impacts on families and communities over the last three decades, as they struggle to care for large numbers of people with a highly stigmatised, chronic, life-limiting illness, with very limited public social protection or formal care services and inadequate healthcare resources. Research has highlighted the gendered nature of unpaid care work within the family ${ }^{1}$ and suggested that children (of both genders) may be increasingly involved in providing care and support to parents/relatives with HIV in the most affected communities ${ }^{2}$. However, the unpaid care work of women and children is often unrecognised and many People Living with HIV and AIDS (PLHA) and those caring for them may experience significant stigma and discrimination and have little access to external support. Commentators have called for greater recognition of the specific needs of unpaid carers of PLHA within international development policy and for a scaling-up of home-based care services for PLHA and their families ${ }^{3}$.

Recent policy meta-narratives however suggest that care is increasingly acknowledged as an issue of global concern. The United Nations Commission on the Status of Women 2009 meeting on 'The equal sharing of responsibilities between women and men, including caregiving in the context of HIV/AIDS' drew attention to the gendered nature of care ${ }^{4}$. Disability rights perspectives, however, challenge the language of 'care' and 'dependence' and disabled people's views have often been overlooked in policy debates about care, including in the recent United Nations discussions. Researchers and disability activists in the global North have debated the tensions between the notions of care, disability, and (in)dependence and the implications for advocacy and policy to support disabled people and carers. However, much of the discussion to date has been viewed through the lens of social policy interventions and disability politics in the global North (particularly the UK) ${ }^{5}$, with a lack of consideration for the ways these issues relate to disabled people, PLHA and carers in the global South.

The relationship between chronic, life-limiting illnesses such as HIV and disability is complex. The vulnerability of disabled people to HIV infection has only recently been recognised and disability issues have been largely neglected in global and national HIV/AIDS policy responses. This is linked to underlying assumptions that disabled people are sexually inactive, unlikely to use drugs and are at less risk of rape and sexual violence. Recent research has refuted these assumptions and revealed that disabled people are particularly susceptible to HIV infection due to a range of factors, including their low socio-economic status and heightened vulnerability to sexual exploitation and abuse (particularly disabled women and girls) compared to non-disabled people; limited sexual health awareness due to low levels of literacy, poor access to education, inaccessible sex education resources and sexual health advice and testing centres ${ }^{6}$. The UN Convention on the Rights of Persons with Disabilities does not explicitly refer to HIV or AIDS in the definition of disability. However, UNAIDS et al. note that:

States are required to recognize that where persons living with HIV (asymptomatic or symptomatic) have impairments which, in interaction with the environment, results in

(C) Ruth Evans and Agnes Atim, 2011. Please cite as: Evans, R. and Atim, A. (2011) 'Care, Disability and HIV in Africa: diverging or interconnected concepts and practices?', Third World Quarterly, 32(8): 1437-1454. 
stigma, discrimination or other barriers to their participation, they can fall under the protection of the Convention ${ }^{7}$.

PLHA are not usually defined as disabled people unless they have specific long term impairments, despite some countries (including the UK and Australia) according protection to PLHA under national disability legislation ${ }^{8}$. The disability movement has been reluctant to regard PLHA as disabled people due to social model perspectives that reject the notion of disability as an 'illness'. Similarly, PLHA rarely identify as disabled people, unless they have permanent physical impairments resulting from HIV that affect their quality of life.

Organisations and networks of PLHA have grown rapidly in the Eastern and Southern African countries most affected by the epidemic in recent years in order to campaign for their rights. The principle of 'Greater Involvement of People Living with or Affected by HIV/AIDS' declared at the 1994 Paris AIDS Summit provided widespread international commitment (in policy rhetoric at least) to the participation of PLHA in tackling the epidemic at all levels. The Treatment Action Campaign in South Africa represents an example of an embodied health movement of 'biological citizens' who successfully advocated for their rights to anti-retroviral therapy and greater government involvement in efforts to tackle the epidemic ${ }^{9}$. While PLHA-led organisations have been able to influence policy agendas to some extent, they have tended to advocate for their rights in isolation from disabled people's organisations in the global South. Meanwhile, disabled people's organisations have increasingly recognised the links between disability and HIV and advocated for national HIV/AIDS policies and programmes that are inclusive of persons with disabilities. The Africa Campaign on Disability and HIV/AIDS, led by the Secretariat of the African Decade of Persons with Disabilities and Handicap International was launched in 2007 at a meeting of disabled people's organisations and service providers from African countries. Despite this growth in advocacy by HIV activists and disabled people, however, the participation of both groups in policy initiatives related to care and support has been limited to date.

This paper explores the divergences and interconnections between the concepts and practices of care, disability and HIV in East Africa. Following an overview of recent literature on disability, embodiment and ethics of care, we outline our research and practice backgrounds. Drawing on qualitative research in Tanzania, we analyse women's embodied health identities and discuss the ways that the emotional interactions between mothers with HIV and their children challenge the conventional distinction between 'care-givers' and 'care-recipients'. Building on learning from the National Community of Women Living with HIV and AIDS in Uganda, we discuss the role that PLHA in East Africa play in providing peer support, homebased care and advocacy for the rights of PLHA and care-givers at local, national and international levels. To conclude, we consider potential avenues for future advocacy and policy on these global concerns.

\section{Disability, HIV and care: contested concepts}

The social model of disability defines impairment as 'the medically defined condition of a person's body/mind' and disability as 'the socially constructed disadvantage based upon impairment ${ }^{10}$. While the distinction between 'impairment' and 'disability' has been crucial to the disability movement in the global North, feminists have highlighted a tendency within social model approaches to equate illness with impairment and deny the materiality of the

(C) Ruth Evans and Agnes Atim, 2011. Please cite as: Evans, R. and Atim, A. (2011) 'Care, Disability and HIV in Africa: diverging or interconnected concepts and practices?', Third World Quarterly, 32(8): 1437-1454. 
body ${ }^{11}$. The focus of the disability movement on the social and environmental barriers associated with the public sphere that prevent the participation of disabled people, to the exclusion of the 'personal' embodied aspects of disability, such as experiences of pain, chronic illness and psycho-social dimensions of impairment, was seen as necessary in the struggle for emancipation ${ }^{12}$. People living with chronic illness therefore occupy an ambivalent position within disability activism and may prefer to identify with those who share their bio-medical diagnosis rather than identifying as 'disabled people'.

Recent approaches to the body, health and illness, however, have emphasised the need to understand the changing materiality of the body and embodied experiences of health and illness in the construction of health identities ${ }^{13}$. James and Hockey argue that health identities are not fixed, but rather are constantly being produced, shaped and resisted through bio-medical and lay discourses of health and illness, social interactions and embodied actions and resources that individuals can access within specific contexts ${ }^{14}$. Broadly informed by social constructionist perspectives, such understandings of embodiment, health and illness have been shown to be particularly relevant in understanding the lived experiences of people with fluctuating and unpredictable chronic illnesses such as multiple sclerosis, arthritis and HIV among others ${ }^{15}$. Drawing on Rabinow's concept of 'biosociality', Hughes suggests that the interests and concerns of 'biosocial' groups and disabled people diverge in a number of ways ${ }^{16}$. Firstly, while the social model stance of the disability movement rejects biomedical discourses and has been reluctant to acknowledge lived experiences of impairment, biomedical diagnosis and impairment are central to the identification of 'biological citizens'. Second, biosocial groups are likely to 'gather and embrace the specialised medical and scientific knowledge associated with their condition' and medicine is perceived as a 'potential ally' in contrast to the disabled people's movement.

Differences in standpoint between disabled people and PLHA are also revealed in the language each group uses to refer to themselves. Disability activists avoid acronyms such as 'PWDs' which could be argued to dehumanise people and express a strong preference for terms which include the word 'people/persons' when referring to 'disabled people' (favoured in social model approaches) or 'persons with disabilities' (used in the United Nations Convention on the Rights of Disabled Persons and increasingly in global contexts). People living with HIV and AIDS have also emphasised the importance of including the words 'people' and 'living with HIV' in language used to refer to themselves rather than more passive biomedical terms such as those 'infected with HIV', 'suffering from HIV/AIDS'. They distinguish between 'HIV' and 'AIDS' rather than conflating them as one condition, since people may live well with HIV for many years, and the high level of stigma is due in large part to the association of AIDS with death. However, the acronym 'PLHA' is widely used by activists and in the literature ${ }^{17}$ and is not considered to dehumanise people living with HIV.

Commentators have discussed the uneasy relationship between care research and disability studies in the global North, highlighting how the concepts of 'care' and 'dependence' may be perceived as oppressive and objectifying from a social model of disability perspective ${ }^{18}$. The interests, needs and perspectives of disabled people are often constructed as in radical opposition to those of 'carers', which has implications for political organising and advocacy by each group ${ }^{19}$. Since the 1970 s, feminists have drawn attention to the unpaid care work

(C) Ruth Evans and Agnes Atim, 2011. Please cite as: Evans, R. and Atim, A. (2011) 'Care, Disability and HIV in Africa: diverging or interconnected concepts and practices?', Third World Quarterly, 32(8): 1437-1454. 
(including domestic work, childcare and caring for disabled or elderly relatives) that women are primarily responsible for within the private sphere. Disability scholars, however, have challenged negative assumptions that disabled people are 'dependents' who are less able to make choices for themselves and that care is a 'burden' for those who are responsible for providing it. They have argued instead that 'independence' needs to be understood 'not as being able to perform activities for oneself without assistance, but as being able to exercise control over whatever help is required in order to achieve chosen goals and objectives, ${ }^{20}$. Thus, disabled people may exercise a substantial level of 'decisional autonomy', even though they may require personal assistance from others to execute those decisions.

Feminist disability scholars have questioned the dichotomy between 'caregivers' and 'carerecipients', since this fails to recognise reciprocity within caring relations and assumes that disabled people are not able to provide care. Morris has highlighted the care provided by disabled women in their roles as mothers and partners ${ }^{21}$. The use of the term 'young carers' and an exclusive focus on support for children who take on caring roles for disabled parents, has led to negative portrayals of disabled people as 'inadequate parents' within the media, research and practice ${ }^{22}$. Disability scholars have challenged such assumptions and called instead for greater recognition of disabled people's parenting roles and the need for formal support and assistance so that disabled parents are not forced to rely on their children (and other family members) to undertake caring tasks ${ }^{23}$.

Despite these debates, care research and disability studies should not necessarily be seen as mutually exclusive. Feminist ethics of care are considered a potentially useful way of theorising care and recognising reciprocity ${ }^{24}$. Tronto and Sevenhuijsen emphasise the interdependence and interconnectedness of human relations, responsibilities and practices of care $^{25}$. Care is regarded as geographically and historically contingent and it is acknowledged that there is no absolute or fixed division of roles between 'care-giver' and 'care-receiver', since we all give and receive care in different contexts and at different times throughout the lifecourse.

Kittay theorises further the power relations imbued in notions of 'care' and 'dependency, ${ }^{26}$. Kittay refers to (paid and unpaid) care as 'dependency work', care-givers as 'dependency workers' and care-recipients as 'charges'. She distinguishes between 'inequality of power' and the 'exercise of domination'. As Fine and Glendinning explain: 'while the care recipient is vulnerable to the abuse of power by the care-giver, the reverse may also be the case; the charge may have power over the worker as a result of social position, wealth, control of employment, through forms of moral blackmail or through the worker's (over-)identification with the charge ${ }^{, 27}$. However, such inequalities of power do not mean that abuse is inherent in the caring relationship, which is ideally based on mutual trust and responsibility. Domination, however, 'represents a breakdown of this mutual trust by either the worker or the charge'.

Kittay suggests that a second level of dependency is based on the reliance of the 'charge' and the 'dependency worker' on 'the provider', who controls the resources needed to provide care and creates the conditions which devalue dependency work. Care-recipients, care-givers and providers are involved in complex interactions, which Kittay terms 'nested dependencies'. In the global North, the welfare state may be considered 'the provider', which alongside health and social care policy and practice, influences the level of support and risk of

(C) Ruth Evans and Agnes Atim, 2011. Please cite as: Evans, R. and Atim, A. (2011) 'Care, Disability and HIV in Africa: diverging or interconnected concepts and practices?', Third World Quarterly, 32(8): 1437-1454. 
impoverishment and exploitation that disabled people and carers may experience. In Tanzania, Uganda and other low income countries in the global South, however, state welfare support is virtually non-existent; hence the notion of a 'provider' needs to take into account power inequalities at the global scale that prevent equal access to healthcare and constrain the ability of governments to provide support to all those who require assistance, as well as social arrangements at the local level.

Within this analysis of care, Fine and Glendinning suggest that 'independence' can be conceptualised as 'relational autonomy'; power should not only be regarded as negative, but rather can be understood as "capability', 'as a form of empowerment - "power to" not "power over" 28 . This echoes Foucauldian notions of the diffuse nature of power, working "from below', which is productive and constitutive of our bodies and subjectivities ${ }^{29}$.

Empowerment is understood in terms of a person's agency and their capacity to do or affect something and 'make a difference'. Furthermore, the analysis of care in terms of 'nested dependencies' at both an interpersonal and structural level enables a focus on the relative powerlessness or autonomy of both care-givers and care-recipients and emphasises how the capacities of both can be enhanced to affect change.

While researchers in the global North have discussed perceptions of care, dependence and autonomy from a disability perspective, few studies have engaged with these ideas in relation to HIV or with regard to the global South. Recent research with families in Tanzania and Namibia, however, has revealed that care is often a two-way process of both giving and receiving care, based on reciprocal, interdependent relations between PLHA and family members $^{30}$. As we discuss,PLHA, including disabled people living with HIV, may provide home-based care for partners, children, other family members and peers with HIV, as well as receiving care themselves. Such interdependent caring relations blur conventional boundaries and assumptions about the needs and interests of 'care-givers' and 'care-recipients', while simultaneously revealing interconnected dependencies and power inequalities at a range of spatial scales.

\section{Research and practice background}

This paper discusses the findings of qualitative research conducted by Ruth Evans with women living with HIV and children caring for them in Tanzania ${ }^{31}$. Purposive sampling techniques were used to recruit participants from rural and urban areas: Dar es Salaam, Mererani and Moshi (urban) and Arusha and Kilimanjaro regions (rural). Semi-structured interviews were conducted with 20 mothers/female relatives living with HIV, 22 young people (aged 11-24) who cared for or used to care for a parent/relative with HIV and 13 NGO workers supporting them. Young people providing care and mothers/relatives receiving care were recruited from the same households wherever possible. Approximately equal numbers of girls (8) and boys (7) aged under 18 participated in the research, but the majority of young adults (aged 18-24) participating were young women (7) with only one young man (aged 18). Mothers/female relatives constituted the entire sample of parents/relatives with HIV and project workers identified very few young people caring for fathers with HIV. Almost all of the women with HIV in the sample had been widowed or had lost their male partner due to AIDS-related illness and a third of the households included one or more children who were also living with HIV. All interviews were conducted in Kiswahili, and transcribed and translated into English with research assistance. Ethical issues were of paramount importance

(C) Ruth Evans and Agnes Atim, 2011. Please cite as: Evans, R. and Atim, A. (2011) 'Care, Disability and HIV in Africa: diverging or interconnected concepts and practices?', Third World Quarterly, 32(8): 1437-1454. 
throughout the study and participants' accounts have been anonymised to protect their identities.

In this paper we also draw on the professional experience of Agnes Atim in her role leading the National Community of Women Living with HIV and AIDS in Uganda (NACWOLA). NACWOLA is a network of HIV-positive women with a membership of over 60,000 across the country. The programmes are funded by Comic Relief (a UK-based charity) and the United States Agency for International Development. NACWOLA's mission is to empower women living with HIV and their families to live a healthy, productive and dignified life without prejudice. This is achieved by recruiting and training HIV-positive women/girls and $\mathrm{men} /$ boys to serve as activists and programme agents in their communities and to enable them to participate in processes and decisions that have an immediate and direct impact on their lives in the present and future. Agnes strives to ensure that HIV-positive women's voices are heard through engagement with policymakers, development partners and other stakeholders at local, national and international levels. To date, NACWOLA has only engaged to a limited extent with disabled people's organisations, such as the National Union of People with Disabilities Uganda and Network of Women with Disabilities, in the areas of policy, law reform and service provision.

\section{Embodied health identities}

Research with people living with HIV and other chronic illnesses has highlighted the significance of bio-medical diagnosis as a 'biographical disruption' and/or 'biographical reinforcement' that often leads to a changed health identity ${ }^{32}$. The narratives of women in Tanzania suggest that diagnosis of their HIV status represented such a 'biographical disruption' that forced them to re-consider their lives and their identities. Several women struggled to reconcile their sense of self with a highly stigmatised health identity, questioning why and how they had become infected. Women who had known about their status for several years before anti-retroviral therapy became freely available felt they were "waiting to die' and were worried about whether their children were also infected. Many women were unaware that their husband/ partner had died of an AIDS-related illness and it was only when they became ill themselves and tried to find out the cause of their husband's death that they discovered their own status. Exposure to risk through unequal heterosexual relationships formed part of some women's narratives of discovering their status. Distrust of medical professionals, combined with feelings of shock and disbelief and the lack of availability of anti-retroviral therapy in Tanzania (and many other Sub-Saharan African countries) until the mid-2000s meant that some women had tests several times at different hospitals before they could accept the diagnosis.

Many women identified the chronic fatigue and unpredictable, episodic nature of HIV-related illness as the most difficult aspect of the disease to deal with. Unpredictable chronic illness and fatigue prevented them from earning a livelihood and performing their social reproductive roles in producing food for the household, caring for their children and undertaking domestic chores. One mother commented: "Sometimes I feel tired, I feel drained of any energy and I'm not able to do any work; general weakness in my body. My body just refuses to function. [...] It changes from time to time; you are better today and worse tomorrow". Fluctuating and severely limited energy can be particularly difficult to manage since it is "unpredictable and resists control',33. Most women relied on earning a livelihood

(C) Ruth Evans and Agnes Atim, 2011. Please cite as: Evans, R. and Atim, A. (2011) 'Care, Disability and HIV in Africa: diverging or interconnected concepts and practices?', Third World Quarterly, 32(8): 1437-1454. 
through agricultural labour or casual work in the informal sector, both of which were physically strenuous. As the main income-earner in female-headed households, the loss of mothers' ability to earn a livelihood often led to chronic poverty. It also undermined women's roles as mothers who provided for their children. As a consequence, children's work in the informal sector often intensified, as they sought to replace their mother's income.

The diversity of physical and emotional effects of living with HIV that women reported reveals the difficulty in generalising about embodied experiences of HIV- and AIDS-related illness and the support needs of PLHA ${ }^{34}$. The invisibility of HIV infection and fluctuation between periods of 'good' and 'ill' health pose a challenge to constructions of PLHA as 'care-recipients' and suggests commonalities with disabled people's experiences of hidden impairments and chronic illnesses. Many of the women in Tanzania thought that they must have been living with HIV for many years, associating the time they became infected with their husband's illness/death and/or the birth of a child who was later discovered to be HIVpositive. The process of coming to terms with their status therefore partly involved reconciling memories of periods of good health with a 'discredited' identity ${ }^{35}$ as a person living with HIV. Furthermore, although the particular dynamics of stigma PLHA experience are likely to be specific to the condition, such experiences of discrimination can be conceptualised as 'psycho-emotional disablism' and attitudinal barriers to participation that disabled people experience ${ }^{36}$. In common with other 'hidden' impairments, PLHA often engage in an on-going process of 'passing' as healthy and managing the presentation of their identity as an HIV-positive individual to others in order to avoid stigmatisation in different contexts. Access to anti-retroviral therapy often helped to alleviate physical symptoms of HIV-related illness (although some women mentioned side-effects of the drugs) and hence could extend the time that PLHA could 'pass' as healthy individuals and conceal their HIV status from family and community members. The embodied experiences of women living with HIV in Tanzania therefore suggest a number of commonalities with the experiences of disabled people with hidden impairments and chronic illnesses.

\section{Interdependent caring relations within families}

Recent research in Africa has revealed that caring relations are often characterised by strong emotional connections between PLHA and those who care for them ${ }^{37}$. Many mothers with HIV and children caring for them in Tanzania reported that they had close, loving relationships and understood each other well. Children played a key role in providing emotional support to their mothers, siblings and other relatives living with HIV, including talking and comforting them, offering advice, giving them hope, reassurance and keeping them company. Despite mothers' illness and the emotional support children provided, however, most children said that they turned to their mother for advice, guidance and support. Mothers/adult relatives with HIV retained their usual position of authority and responsibility for decision-making within the household, despite sometimes being nursed in bed for several months. The continued parenting role of mothers refutes negative assumptions about the competence of parents living with HIV to provide good care for their children.

Some mothers' and young people's narratives demonstrate a strong sense of empathy and understanding of the emotional pressures the other person in the caring relationship may be experiencing. Husna, a mother with HIV, reflected on why Juliette (aged 20) had greater caring responsibilities than her other daughters: "I feel she is the one who understands my

(C) Ruth Evans and Agnes Atim, 2011. Please cite as: Evans, R. and Atim, A. (2011) 'Care, Disability and HIV in Africa: diverging or interconnected concepts and practices?', Third World Quarterly, 32(8): 1437-1454. 
situation better. She is very compassionate. It is obvious that she really depends on me and I on her". Juliette, who was studying at a teacher training college away from home during term-time, commented on the emotional dimensions of her caring responsibilities:

Whenever I get a letter from home saying she is very poorly, I can't concentrate at all. I am filled with thoughts like what would happen to us if she died. I have my younger sisters, I would be the one to look after for them. It is better when she is alive, I feel as though she is helping me in a way because she inspires me with hope. I feel very much at peace seeing her alive.

Such close emotional connections within caring relationships help to ensure that care is based on (among others) the ethical value of 'responsiveness ${ }^{38}$. These connections highlight the complexity of caring relations within families and reveal fluidity between the roles of 'caregivers' and 'care-recipients', since both children and parents/relatives with HIV 'give' and 'receive' care. As Juliette's comments suggest, the survival and continued presence of parents living with HIV in their children's lives often enhances young people's wellbeing and protects them from negative outcomes ${ }^{39}$. This gives added impetus to international commitments to achieve universal access to treatment for all those who need it.

Although women and girls are usually expected to be the primary caregivers in many African countries (and elsewhere globally) ${ }^{40}$, the research in Tanzania suggests that boys and young men provide care when female relatives are not available. Boys undertaking caring tasks that challenged gender norms could be particularly marginalised. Farida explained that she was cared for by her youngest child, Babu (aged 14) because her five older children had all moved out of home and refused to visit: "I have a family but they have stigmatized me. They don't care about me, the only child with me is this 14-year-old one". Babu expressed anger and resentment that he received no help from his older sisters in caring for his mother and undertaking domestic chores: "I feel bad [about caring] because I feel like I have been ostracized by the family. [I don't like] doing work that I shouldn't be doing, like washing the dishes, mopping the floor. [...] Because my sisters are there. [...] I don't like carrying on caring for mum when there are other relatives around, but I have to".

This example reveals the power inequalities and vulnerabilities that may affect both carerecipients and care-givers. The potential abuse of power by the care-giver present in most caring relations is balanced to some extent by children's relative powerlessness and dependence on their parent/adult relative for love and guidance. As Kittay comments: 'although familial caregivers are as capable of neglect and abuse as strangers paid to care, affective bonds that normally form between family members offer important defences against the harmful behaviour, especially when supports are available to ease hardships, ${ }^{41}$. Coresidence and the low socio-economic status of children, combined with close relationships and a strong sense of moral responsibility towards their parent, meant that young people had little option but to stay with their parent and support them during their illness. This means that both parents/relatives with HIV and children caring for them are mutually dependent on each other and hence 'domination', that is, the breakdown of mutual trust by either the 'dependency worker' or the 'charge' appears unlikely.

(C) Ruth Evans and Agnes Atim, 2011. Please cite as: Evans, R. and Atim, A. (2011) 'Care, Disability and HIV in Africa: diverging or interconnected concepts and practices?', Third World Quarterly, 32(8): 1437-1454. 
In Babu's and other cases, however, older (usually male) siblings had moved out of the household and were unwilling to take on or help with caring responsibilities. The absence of social supports for care-givers, combined with socio-cultural constructions of care and young men's more privileged position in gender and age hierarchies, meant that older male siblings were able to refuse to provide care and instead sought to establish their own 'independent' lives without such caring responsibilities. This could be regarded as the exercise of 'domination' over the care-recipient and their younger siblings. Such gendered and agerelated norms of care are reflected in the much smaller proportion of young men (aged 18-24) interviewed who were caring for a parent/relative ( 1 out of 8 ) compared to young women of the same age ( 7 out of 8 ).

Many mothers were concerned about how caring affected children's emotional wellbeing and sought to protect children from potential 'biographical disruption' associated with their illness $^{42}$. Husna said of Juliette's caring responsibilities:

She has a big burden on her young shoulders. I sometimes feel she is overwhelmed by worry. She thinks a lot about me and I think she dreads the day I will die because she will have to provide for her younger sisters. [...] I am sad but I have no choice. I feel sorry for her because I feel she is carrying the burden of someone else's responsibility, but that someone else isn't there.

Juliette perceived her caring responsibilities as 'daunting' at times, but felt a moral obligation to support her mother since their relatives stigmatised the family and they lacked alternative sources of support: "The responsibilities are many and I am still young. At times it is daunting. But there is no one else to help so I have to do it". Thus, despite the development of interdependent caring relations, mutual trust and responsibility, some mothers and children simultaneously perceived care as a 'burden' which could have negative physical, emotional and educational impacts. The 'diminished autonomy' of care-givers here can be regarded as a consequence of the limited material, healthcare and social supports available to PLHA and their families in Tanzania. The conditions of 'dependency work' and vulnerability to chronic poverty and exploitation are created by care-givers' and care-recipients' unequal relation to 'the provider' within the 'nested dependencies' of care ${ }^{43}$. This is perhaps most evident when the care-givers are children who occupy a weak socio-economic position and are responsible for caring for mothers/female relatives with HIV in lone parent households without adequate external support.

\section{Peer support, participation and advocacy of people living with HIV and AIDS}

Opportunities for disabled people and other marginalized groups to meet, share experiences and develop peer support in safe spaces are often perceived as empowering for individuals. They can also foster collective action to challenge discrimination and barriers to participation ${ }^{44}$. Peer support among those who identify with a particular health identity is often focused on coming to terms with the diagnosis, sharing embodied experiences and learning about biomedical health and treatment issues associated with their condition ${ }^{45}$. Many women interviewed in Tanzania regularly attended peer support groups, which they felt provided opportunities for women to share experiences and give informal advice about HIV-related issues, including adherence to treatment, nutrition and gaining access to informal material support. As one mother said: "Here at home I am lonely, there are no women of my

(C) Ruth Evans and Agnes Atim, 2011. Please cite as: Evans, R. and Atim, A. (2011) 'Care, Disability and HIV in Africa: diverging or interconnected concepts and practices?', Third World Quarterly, 32(8): 1437-1454. 
age that I can talk to. When I go there, I am comforted. I mix with people who have similar problems to mine. We exchange ideas and learn about a lot of things".

While developing peer support and living more positively with HIV is important in reducing isolation and may enhance PLHA's 'relational autonomy', it is unclear how this may translate into wider collective action and politicization as 'biological citizens'. Although peer support groups were valued, they were not usually linked to national networks of PLHA or to transnational activism. Beckman and Bujra found that access to anti-retroviral therapy may allow PLHA in Tanzania to hide their status, avoid stigmatisation and facilitate 'their new quest for work, partners and a "normal life"'. Being able to 'pass' as 'normal' and conceal their illness from others, however, may mean that people no longer identify as PLHA and disengage from peer support and activist activities. This reveals contradictions within the concept of "biological citizenship" 46 .

In Uganda, networks of PLHA and individuals have supported home-based care since the peak of the epidemic in the early 1990s, in order to reduce the barriers to care, provide peer support and bring healthcare to those unable to travel to a clinic. PLHA play a crucial role in providing comprehensive non-clinical nursing, palliative, psychosocial, and spiritual care to their peers. With the scale-up of anti-retroviral therapy, PLHA-led organisations, such as NACWOLA, have trained PLHA as home-based care-givers and as community support agents based in health facilities in order to provide treatment adherence support. This helps to reduce the likelihood of PLHA who have tested positive subsequently failing to return to health facilities to receive treatment and other services. NACWOLA has also worked in partnership with the Network of Women with Disabilities to train disabled women living with HIV to provide support to their peers in Bugiri, eastern Uganda.

While such PLHA-led activities could be regarded as serving the neoliberal donor-driven agenda of promoting participation and providing alternative service delivery ${ }^{47}$, NACWOLA's experiences suggests that the participation of PLHA, including disabled women living with $\mathrm{HIV}$, in care-giving can have several benefits. It helps to reduce feelings of dependency on family members, thereby alleviating potential tensions and emotional pressures within caring relations and reducing the risk of 'domination'. PLHA care-givers are motivated to provide the best care they can because they know that they may develop such care needs themselves in future, thereby fostering an environment of 'reciprocal social co-operation" ${ }^{48}$. NACWOLA recognises, however, that care-givers need to be supported in their caring roles. The 'Care for the Carers' programme provides income-earning opportunities and mobilises care-givers to make small cash contributions to support members in need. NACWOLA Centres provide a safe space where care-givers can share experiences, grow vegetables, massage one another and learn handicrafts. These activities appear to help relieve the stress associated with caregiving and prevent 'burnout', which has been identified as a significant risk if care-givers providing high levels of care over extended periods are unsupported ${ }^{49}$.

NACWOLA also challenges the inadequacies of care provision by building the capacities of women and girls living with HIV to participate in decision-making processes. NACWOLA has successfully lobbied on a range of issues related to the rights of women and girls living with HIV and representatives participate in local, national, regional and international forums, including the African Commission on Human and Peoples' Rights and the United Nations

(C) Ruth Evans and Agnes Atim, 2011. Please cite as: Evans, R. and Atim, A. (2011) 'Care, Disability and HIV in Africa: diverging or interconnected concepts and practices?', Third World Quarterly, 32(8): 1437-1454. 
Commission on the Status of Women 2009 meeting. NACWOLA has also engaged in collective advocacy with the National Union of People with Disabilities Uganda (NUPIDU) at the global and national levels.

Several challenges remain, however, in influencing global and national policies on the care and support of PLHA. Firstly, care and support issues have not been prioritised to date within global responses to the epidemic. The emphasis on achieving quantifiable targets by governments, international donors and United Nations agencies, particularly in the light of universal access targets and Millennium Development Goal 6, means that the scale-up of anti-retroviral therapy has dominated funding and programme responses. Increased access to anti-retroviral therapy has led to a welcome reduction in AIDS-related mortality and PLHA accessing treatment who have an adequate, nutritional diet are now able to lead relatively 'normal' lives. This has resulted, however, in a perception that care and support services are no longer required. HIV is viewed as a chronic illness that can be effectively managed through bio-medical intervention, rather than as a terminal illness, which may result in a reduction in funding for dedicated community-based HIV services ${ }^{50}$. Furthermore, the fact that most care-givers are women and girls and the lack of a clear definition and narrow understandings of care among policymakers and practitioners hinder the development of services and support ${ }^{51}$. This is linked to gendered assumptions about women's 'natural' caring roles and the widespread devaluing of care work globally. Limited civil society advocacy and weak global governance of HIV care and support activities have further hindered implementation. Finally, unequal gender and generational relations in many cultural contexts mean that the voices of women, girls and boys who are caregivers, disabled people and/or living with HIV are often marginalised in decision-making processes from the macro- to the micro-levels.

\section{Conclusion}

This article has explored the complex divergences and interconnections between the concepts of care, disability and HIV in the context of East Africa. The research in Tanzania revealed that women's on-going negotiations of their health identities were shaped by a complex range of factors, including:

- biomedical diagnosis and the ways women had discovered their HIV status;

- embodied experiences of living with fluctuating chronic illness;

- gendered roles as mothers and wives;

- the quality of relationships with children and other family and community members;

- access to material resources, livelihood options, external support, treatment and care. Biomedical diagnosis and chronic illness represented a 'biographical disruption' for many women, as they struggled to reconcile their sense of self with a 'discredited' social identity as a person living with a highly stigmatised illness. The invisible nature of HIV infection, embodied experiences of episodic illness and the psycho-emotional dimensions of their impairment suggest that PLHA share a number of commonalities with disabled people with hidden impairments and chronic illnesses. Ill health, reduced capacity to earn a livelihood and stigmatisation meant that mothers had to rely on their children for care, which undermined their identities as 'mothers'. Many children felt a moral obligation to care for their mother/relative due to socio-cultural norms and a lack of alternatives.

(C) Ruth Evans and Agnes Atim, 2011. Please cite as: Evans, R. and Atim, A. (2011) 'Care, Disability and HIV in Africa: diverging or interconnected concepts and practices?', Third World Quarterly, 32(8): 1437-1454. 
The mutual emotional support and interdependent caring relations that develop between mothers living with HIV and their children and between PLHA and their peers who require support in Tanzania and Uganda challenge the conventional dichotomy between the needs and interests of 'care-givers' and 'care-recipients'. Indeed, the research suggests that caring relations are often characterised by a high level of 'responsiveness' and mutual trust, as each person in the caring relationship seeks to understand the other's perspective in order to provide the best care they can. However, young people's competencies to provide 'good care' were often undermined by poverty, stigma and ostracism and limited access to external support. Care could thus simultaneously be perceived by both mothers and children as a 'burden' which could have negative impacts on children's present and future lives. Such experiences reveal the complex, often contradictory nature of power inequalities and 'nested dependencies' within caring practices and relations. Both care-givers and care-recipients in East Africa occupy a relatively powerless position in relation to broader social supports and state care provision, which diminish their autonomy.

NACWOLA's work to train and support PLHA, including disabled women living with HIV, as home-based care-givers in Uganda appears to help alleviate emotional pressures within caring relations and reduce feelings of 'dependency' on family care-givers. Our research highlights the need for such home-based care initiatives to consider young people's views and support needs as 'care-givers', as well as those of parents/relatives with HIV, disabled people and other family members. Peer support groups enable PLHA to share embodied experiences and knowledge and reduce their isolation. Similar self-help groups for 'caregivers' could facilitate the development of peer support and provide access to resources. Such safe spaces in the community may provide important opportunities for both care-givers and care-recipients to develop their capacities to act and achieve greater levels of 'relational autonomy'.

PLHA in East Africa have identified on the basis of their biomedical diagnosis rather than as 'disabled people' to date. The emphasis of HIV activism on improving access to medical treatment rather than on increasing access to support and care assistance contrasts with the advocacy and politics of the disability movement. While access to healthcare represents a crucial human right, treatment also enables PLHA to pass as 'normal' and conceal their illness. This ambivalence in the concept of 'biological citizenship' for PLHA weakens the potential for collective identification and involvement in activism ${ }^{52}$. Nevertheless, NACWOLA's work to empower women living with HIV to realise their rights to treatment, care and support could be extended to collectively challenge the structural and relational barriers to participation that PLHA, disabled people and care-givers experience, in recognition of the common vulnerabilities and dependencies that these groups experience. Recent policy initiatives such as The Africa Campaign on Disability and HIV/AIDS ${ }^{53}$ suggest potential opportunities for PLHA-led organisations and disabled people's organisations to form new alliances and partnerships. This would enable PLHA and disabled people to advocate for care and support together, in recognition of the interconnections between HIV, disability and care.

African organisations of PLHA and home-based care-givers have achieved some success in influencing the global care policy agenda, evidenced in the Agreed Conclusions of the United Nations Commission on the Status of Women 2009 meeting. The voices and needs of

(C) Ruth Evans and Agnes Atim, 2011. Please cite as: Evans, R. and Atim, A. (2011) 'Care, Disability and HIV in Africa: diverging or interconnected concepts and practices?', Third World Quarterly, 32(8): 1437-1454. 
disabled people, however, have been neglected, resulting in disabled people being framed as a 'care burden" 54 . The rapid adoption and ratification of the United Nations Convention on the Rights of Persons with Disabilities in many countries has resulted in a high level of state and civil society mobilisation around disability in recent global policy debates. Given the increasing recognition of disabled people's rights, significant possibilities exist for mutual learning and cross-movement mobilisation ${ }^{55}$ of disabled people, PLHA and care-givers. Collective advocacy would help to challenge the conventional dichotomy between 'caregivers' and 'care-recipients' and ensure that policy, service provision and practice reflect the perspectives of all those involved in care, whilst acknowledging diversity within and between each group. Transnational cross-movement advocacy, however, needs to be accompanied by strong commitments and action on the part of states and global institutions to address structural inequalities and enable the voices of marginalised groups to influence decisionmaking processes.

\section{Acknowledgements}

We are very grateful to the young people, parents/relatives and NGO staff in Tanzania for sharing their experiences and the Economic and Social Research Council for funding the study. Our sincere gratitude also goes to NACWOLA members involved in HIV service delivery and advocacy for the enormous sacrifices they make and their expertise in improving the wellbeing of people living with HIV in Uganda. Special thanks to Nancy Okunu in her role as the national chairperson of the Board of Directors of NACWOLA for her exceptional leadership over the last three years. We also thank NACWOLA's donors for funding and supporting the work. We also wish to thank Harriet Ward, Helen Meekosha, Karen Soldatic, the anonymous reviewers, and especially Sophie Bowlby, for their helpful comments on the paper.

${ }^{1} \mathrm{~F}$ Thomas, 'Stigma, fatigue and social breakdown: exploring the impacts of HIV/AIDS on patient and carer wellbeing in the Caprivi region, Namibia', Social Science and Medicine, 63, 2006, pp 3174-87.

${ }^{2}$ E Robson, N Ansell, US Huber, WTS Gould and L van Blerk 'Young caregivers in the context of the HIV/AIDS pandemic in sub-Saharan Africa', Population, Space and Place, 12, 006, pp 93-111; R Evans and S Becker, Children Caring for Parents with HIV and AIDS: Global Issues and Policy Responses, Bristol: The Policy Press, 2009.

${ }^{3}$ E Nsutebu, J Walley, E Mataka and C Simon 'Scaling-up HIV/AIDS and TB home-based care: lessons from Zambia', Health Policy and Planning, 16(3), 2001, pp 240-7; J Ogden, S Esim, and C Grown, 'Expanding the care continuum for HIV/AIDS: bringing carers into focus', Health Policy and Planning, 21(5), 2006.

${ }^{4} \mathrm{~K}$ Bedford, 'Harmonizing global care policy? Care and the Commission on the Status of Women', Gender and Development Programme Paper No. 7, February 2010, United Nations Research Institute for Social Development.

${ }^{5} \mathrm{G}$ Parker and $\mathrm{H}$ Clarke, 'Making the ends meet: do carers and disabled people have a common agenda?', Policy and Politics, 30(3), 2002, pp 347-359; T Kröger, 'Care research and disability studies: nothing in common?', Critical Social Policy, 29(3), 2009, pp 398-420. ${ }^{6}$ WHO, Community-based Rehabilitation: CBR Guidelines Supplementary Booklet, ISBN 978924154805 2, WHO: Geneva, 2010,

www.who.int/disabilities/cbr/guidelines/en/index.html, accessed October 2010; J Hanass, and S Nixon, 'The fields of HIV and disability: past, present and future', Journal of the

(C) Ruth Evans and Agnes Atim, 2011. Please cite as: Evans, R. and Atim, A. (2011) 'Care, Disability and HIV in Africa: diverging or interconnected concepts and practices?', Third World Quarterly, 32(8): 1437-1454. 
International AIDS Society, 12(28), 2009, www.jiasociety.org/content/12/1/28, accessed October 2010.

${ }^{7}$ UNAIDS, WHO and OHCHR, Disability and HIV Policy Brief, UNAIDS, WHO and OHCHR, April 2009, p 1.

${ }^{8}$ Disability Rights Commission, A Guide to the Disability Discrimination Act for People with HIV, Cancer and MS, December 2005, DRC, www.drc-gb.org, accessed October 2010; Hanass-Hancock and Nixon, 'The fields of HIV and disability'.

${ }^{9}$ S Leclerc-Madlala 'Popular responses to HIV/AIDS and policy', Journal of Southern African Studies, 31 (4), 2005, pp 845-856.

${ }^{10} \mathrm{~S}$ Wendell, 'Unhealthy disabled: treating chronic illnesses as disabilities', Hypatia, 16(4), 2001, p 22.

${ }^{11}$ J Morris Pride Against Prejudice: Transforming Attitudes to Disability, Philadelphia: New Society Publishers, 1991; S Wendell, 'Unhealthy disabled', pp 17-33.

${ }^{12}$ B Hughes, 'Disability activisms: social model stalwarts and biological citizens', Disability and Society, 24 (6), 2009, pp 677-688; D Reeve 'Negotiating psycho-emotional dimensions of disability and their influence on identity construction', Disability and Society, 17(5), 2002, pp 493-508.

${ }^{13}$ H Parr and R Butler, 'New geographies of illness, impairment and disability', in R. Butler and H. Parr (eds) Mind and Body Space: Geographies of Illness, Impairment and Disability, London and New York: Routledge, 1999, pp1-24.

${ }^{14}$ A James and J Hockey, Embodying Health Identities, Houndmills, Basingstoke: Palgrave Macmillan, 2007, p 10.

${ }^{15}$ I Dyck, 'Hidden geographies: the changing lifeworlds of women with multiple sclerosis', Social Science and Medicine, 40 (3), 1995, pp 307-20; Wendell, 'Unhealthy disabled'.

${ }^{16}$ Hughes explains that Rabinow's (1996) notion of 'biosociality' refers to the process by which biological similarity becomes a focus of community, association and collective action. Hughes, 'Disability activisms', p 678.

${ }^{17} \mathrm{~N}$ Beckmann and J Bujra, "“The politics of the queue": The politicization of People living with HIV/AIDS in Tanzania', 41(6), 2010, pp 1041-1064.

${ }^{18}$ Parker and Clarke, 'Making the ends meet'; M Fine and C Glendinning, 'Dependence, independence or inter-dependence? Revising the concepts of 'care' and 'dependency', Ageing and Society, 25, 2005, pp 601-621.

${ }^{19}$ Bedford, 'Harmonizing global care policy?'

${ }^{20}$ Fine and Glendinning, 'Dependence, independence or inter-dependence? ', p 610.

${ }^{21}$ Morris, Pride Against Prejudice.

${ }^{22}$ L Keith and J Morris, 'Easy targets: a disability rights perspective on the "children as carers" debate', Critical Social Policy, 44/45, 1995, pp 36-57; J Stables and F Smith, "Caught in the Cinderella trap": narratives of disabled parents and young carers", in R. Butler and H. Parr (eds) Mind and Body Spaces. London: Routledge, 1999, pp 256-68.

${ }^{23}$ M Wates, Supporting Disabled Adults in their Parenting Role. York: York Publishing Services, 2002.

${ }^{24}$ Kröger, 'Care research and disability studies'; Fine and Glendinning, 'Dependence, independence or inter-dependence?'.

${ }^{25} \mathrm{~J}$ Tronto, Moral Boundaries. A Political Argument for an Ethic of Care, New York and London: Routledge, 1993; S Sevenhuisjsen, Citizenship and the Ethics of Care. Feminist Considerations on Justice, Morality and Politics, London and New York: Routledge, 1998.

(C) Ruth Evans and Agnes Atim, 2011. Please cite as: Evans, R. and Atim, A. (2011) 'Care, Disability and HIV in Africa: diverging or interconnected concepts and practices?', Third World Quarterly, 32(8): 1437-1454. 
${ }^{26}$ E F Kittay, Love's Labor: Essays on Women, Equality and Dependency, Routledge, New York, 1999; E F Kittay, 'When caring is just and justice is caring: justice and mental retardation', in E F Kittay and E Feder, Eds., The Subject of Care: Feminist Perspectives on Dependency, Lanham: Rowman and Littlefield, 2002, pp.257-276.

${ }^{27}$ Fine and Glendinning, 'Dependence, independence or inter-dependence?', p.613.

${ }^{28}$ Fine and Glendinning, 'Dependence, independence or inter-dependence?', p.616.

${ }^{29}$ Foucault M, Discipline and Punish: the Birth of the Prison, London, Tavistock, 1977.

${ }^{30} \mathrm{R}$ Evans and F Thomas, 'Emotional interactions and an ethic of care: caring relations in families affected by HIV and AIDS', Emotions, Space and Society, 2, 2009, pp.111-119.

${ }^{31}$ This was part of a larger study funded by the UK Economic and Social Research Council that investigated the experiences, needs and resilience of children caring for parents and relatives with HIV in Tanzania and the UK, led by Ruth Evans and Saul Becker, grant number RES-000-22-1732-A.

${ }^{32} \mathrm{~S}$ Wilson, "When you have children, you're obliged to live": motherhood, chronic illness and biographical disruption', Sociology of Health and Illness, 29(4), 2007, pp 610-629.

${ }^{33}$ Wendell, 'Unhealthy disabled'.

${ }^{34}$ R Wilton, 'Qualitative health research: negotiating life with HIV/AIDS', Professional Geographer, 51(2), 1999, pp 254-64.

${ }^{35}$ E Goffman, Stigma: Notes on the Management of Spoiled Identity, London: Penguin Books, 1963.

${ }^{36}$ Reeve, 'Negotiating psycho-emotional dimensions of disability'.

${ }^{37}$ Evans and Thomas, 'Emotional interactions'; A Chimwaza and S Watkins, 'Giving care to people with symptoms of AIDS in rural sub-Saharan Africa', AIDS Care, 16(7), 2004, pp 795-807.

${ }^{38}$ Tronto, Moral Boundaries.

${ }^{39}$ Evans and Becker, Children Caring for Parents with HIV; R Bray, A Literature Review on Child Carers in Angola, Nigeria, Uganda and Zimbabwe, Unpublished report, Pretoria: Save the Children UK, 2009.

${ }^{40}$ Ogden et al., 'Expanding the care continuum for HIV/AIDS'; Evans and Thomas, 'Emotional interactions'.

${ }^{41}$ Kittay, 'When caring is just and justice is caring', p.269.

${ }^{42}$ Wilson, "When you have children, you're obliged to live".

${ }^{43}$ Kittay, 'When caring is just and justice is caring'.

${ }^{44}$ M Oliver, The Politics of Disablement, Basingstoke: Macmillan and St Martin's Press, 1990.

${ }^{45}$ Hughes, 'Disability activisms'; Beckmann and Bujra, “"The politics of the queue"”.

${ }^{46}$ Beckmann and Bujra, "The politics of the queue", p.1056.

${ }^{47} \mathrm{C}$ McIlwaine, 'From local to global to transnational civil society: reframing development perspectives on the non-state sector', Geography Compass, 1(6), 2007, pp. 1252-1281.

${ }^{48}$ Kittay, 'When caring is just and justice is caring', p.271.

${ }^{49}$ Evans and Thomas, 'Emotional interactions'

50 Evans and Becker, Children Caring for Parents with HIV and AIDS.

${ }^{51}$ A holistic definition of HIV care and support was recently proposed in: What do we really mean by 'HIV care and support'? Progress towards a comprehensive definition, HIV Care and Support Working Group of the UK Consortium on AIDS and International Development, London, 2008, www.aidsconsortium.org.uk.

(C) Ruth Evans and Agnes Atim, 2011. Please cite as: Evans, R. and Atim, A. (2011) 'Care, Disability and HIV in Africa: diverging or interconnected concepts and practices?', Third World Quarterly, 32(8): 1437-1454. 
${ }^{52}$ Beckmann and Bujra, "The politics of the queue"”; Hughes, 'Disability activisms'.

${ }^{53}$ Secretariat of the African Decade of Persons with Disabilities and Handicap International (not dated) Africa Campaign on Disability and HIV and AIDS Brochure,

www.africacampaign.info/uploads/media/campaign_brochure_english_version_pdf [accessed 30/10/10].

${ }^{54}$ Bedford, 'Harmonizing global care policy?' p 18.

${ }^{55}$ Kröger, 'Care research and disability studies'.

(C) Ruth Evans and Agnes Atim, 2011. Please cite as: Evans, R. and Atim, A. (2011) 'Care, Disability and HIV in Africa: diverging or interconnected concepts and practices?', Third World Quarterly, 32(8): 1437-1454. 